\title{
The art of body mapping: A methodological guide for social work researchers
}

\author{
Michelle Skop Wilfrid Laurier University, Canada
}

\begin{abstract}
INTRODUCTION: The purpose of this Canadian social work research was to explore the healthcare experiences of men and women with a diagnosis of fibromyalgia (FM), a chronic condition of unknown origin.

METHODS: This study had a total sample of 35 Southwestern Ontarians who participated in two separate qualitative methods of data collection. Ten participants completed in-depth interviews, while 25 participants engaged in body mapping, an arts-based research method, within a series of focus group sessions. The latter method for data collection is the focus of this article. This material provides social work researchers with a methodological road map by outlining the design and implementation of the body mapping process, sharing the lessons learned in data collection and addressing practical and ethical considerations for future studies.

FINDINGS: This research found that: (a) participants experienced structural barriers to accessing healthcare services and unsupportive attitudes from healthcare providers; (b) participants' healthcare experiences were affected by their gender, age, class and race; and (c) participants used self-management strategies to cope with healthcare barriers. The study also found that the body mapping process had therapeutic value.

CONCLUSION: This research contributes information for the transformation of healthcare policies, programmes and clinical practices for the FM population. As a form of applied research, the body mapping process has also helped to empower a marginalised population while promoting innovative forms of social work research.

KEYWORDS: body mapping, arts-based research, methodology, health, fibromyalgia
\end{abstract}

Art is a reflexive process of representing people's inner and outer worlds. Art has a multitude of intentions: it can be created by people, groups and communities for the purpose of self-expression, social justice, community building and qualitative inquiry. Art moves beyond the limitations of words by offering alternative forms of communication to convey the depth and complexity of embodied experiences and emotions (Baerg, 2003). For this reason, researchers have adopted and adapted literary, performative and visual arts as methods of exploring experiences and social interactions. Although traditional academic discourses perpetuate epistemological dichotomies of science/objectivity/reason versus art/subjectivity/feeling, arts-based research (ABR) methodologies have slowly gained recognition and credibility within research communities (Eisner, 2006).

A relatively new form of $A B R$ is body mapping, a process of creating life-size drawings that represent people's identities within their social contexts. In 2002, body mapping evolved from the Memory Box Project, a programme created by clinical
AOTEAROA

NEW ZEALAND SOCIAL WORK 28(4), 29-43.

CORRESPONDENCE TO: Michelle Skop mskop@wlu.ca 
psychologist Jonathan Morgan at the University of Cape Town to help South African women with HIV/AIDS record their lives as family keepsakes (Devine, 2008). Morgan's project was adapted by South African artist Jane Solomon into an art therapy whereby women with HIV/ AIDS use imagery and words to narrate their life journeys. In addition to art therapy, body mapping can be used for advocacy, providing treatment information and support and in participatory research (Solomon, 2002). Internationally, the empirical literature on body mapping has burgeoned in the fields of social science, health and education on topics including HIV / AIDS (MacGregor, 2008; Maina, Sutankayo, Chorney, \& Caine, 2014), undocumented workers (Gastaldo, Magalhaes, Carrasco, \& Davy, 2012), refugee youth (Davy, Magalhaes, Mandich, \& Galheigo, 2014), sexual health (Ramsuran \& Lurwengu, 2008; Senior, Helmer, Chenhall, \& Burbank, 2014), child poverty (Mitchell, 2006), gendered violence (Sweet \& Escalante, 2015) and occupational dance injury (Tarr \& Thomas, 2011).

There is no single method of body mapping. The previously mentioned studies encompass various forms of body mapping but do not provide enough detail about research design implementation and visual analysis procedures. Currently, there are two published manuals about body mapping (Gastaldo et al., 2012; Solomon, 2002). Solomon's manual provides instructions on body mapping as an art therapy modality, whereas Gastaldo et al.'s (2012) manual details body mapping as a research method in the context of individual interviews. Because I could not find published material outlining how body mapping could be used as a research method within group settings, I adapted Gastaldo et al.'s (2012) body mapping method during my $\mathrm{PhD}$ research about chronic illness and healthcare.

Through the research process, I discovered that there is methodological artistry involved in transforming abstract inquiries about human experience into concrete arts-based activities, while fostering a safe environment where participants can express themselves. This work naturally involves analysing the data in a manner that conveys the richness of participants' embodied experiences. Given these complexities, the purpose of this article is to provide social work researchers with a methodological road map by describing how I designed and implemented this body mapping research, weaving in lessons learned and practical and ethical considerations for future studies.

\section{Methods}

\section{Research overview}

I conducted the research to explore the healthcare experiences of men and women with a diagnosis of fibromyalgia (FM). Before doing so, the research received approval from Wilfrid Laurier University's Research Ethics Board. FM is a chronic condition prevalent in $2 \%-3 \%$ of Canadians and primarily diagnosed in women (Fitzcharles et al., 2013). Symptoms include chronic widespread pain, fatigue, sleep disturbances, cognitive difficulties and sensitivity to sensory stimuli (Wolfe, 2009). The condition is often mislabelled as a psychosomatic condition because the aetiology remains unknown (Wolfe, 2009). The impetus for this research was based on my direct social work practice coordinating home healthcare services and observing that patients with FM often experienced barriers in accessing healthcare resources and discrimination from healthcare providers. I was interested in conducting applied research using a creative methodology in order to help empower people marginalised by FM, to decrease social stigma and to potentially promote changes to healthcare policies.

The research question was: How do men and women with a diagnosis of FM experience interactions with healthcare providers? The research was epistemologically informed by intersectionality, a conceptual framework based on "the critical insight that race, class, 
gender, sexuality, ethnicity, nation, ability and age operate not as unitary, mutually exclusive entities, but as reciprocally constructing phenomena that in turn shape complex social inequalities" (Hill Collins, 2015, p. 2). I incorporated the theory of intersectionality into this research because previous FM studies had not explored whether healthcare experiences were shaped by interconnected identities, including gender, race, class and age. The research design included individual interviews, focus groups and body mapping within these groups (see Figure 1 for an example of a body map).

\section{Rationale for using body mapping}

There were multiple reasons for utilising body mapping as a part of the research design. First, body mapping is considered a suitable methodology "for gaining access to people's perceptions of their bodies and to the explanatory models which people bring into encounters with health care workers" (Cornwall, 1992, p. 1). Second, body mapping helped to fill a methodological gap in the literature, as previous FM studies have not used ABR. Third, body mapping is a holistic method of blending the mind, body and social context. Debates about FM have revolved around whether this condition is located in the mind or body. However, body mapping moves beyond the Cartesian dualism of the medical model by helping the participants reflect upon the connection of their minds, bodies, feelings, thoughts, experiences and social interactions. Fourth, body mapping provides a non-verbal method for expressing "experiential states", such as pain, discomfort and frustration, which may be difficult to verbally articulate (Mitchell, 2006, p. 341). These feeling states can be illuminated by the freedom to frame the body in personal ways and to reject standardised medical representations of FM. The standardised FM body, represented in FM informational material, has black dots scattered on the fronts, backs and sides of nude female figures to represent the location of tender points. Fifth, body mapping can stimulate insights that may not arise using traditional qualitative approaches. This process entails "a less directive interviewing style" whereby participants' visual descriptions are probed by the researcher (Cornwall, 1992, p. 1) and fellow focus group participants. Through dialogue, participants can reflect upon the context in which their body maps were produced. During this process, ample time is available for

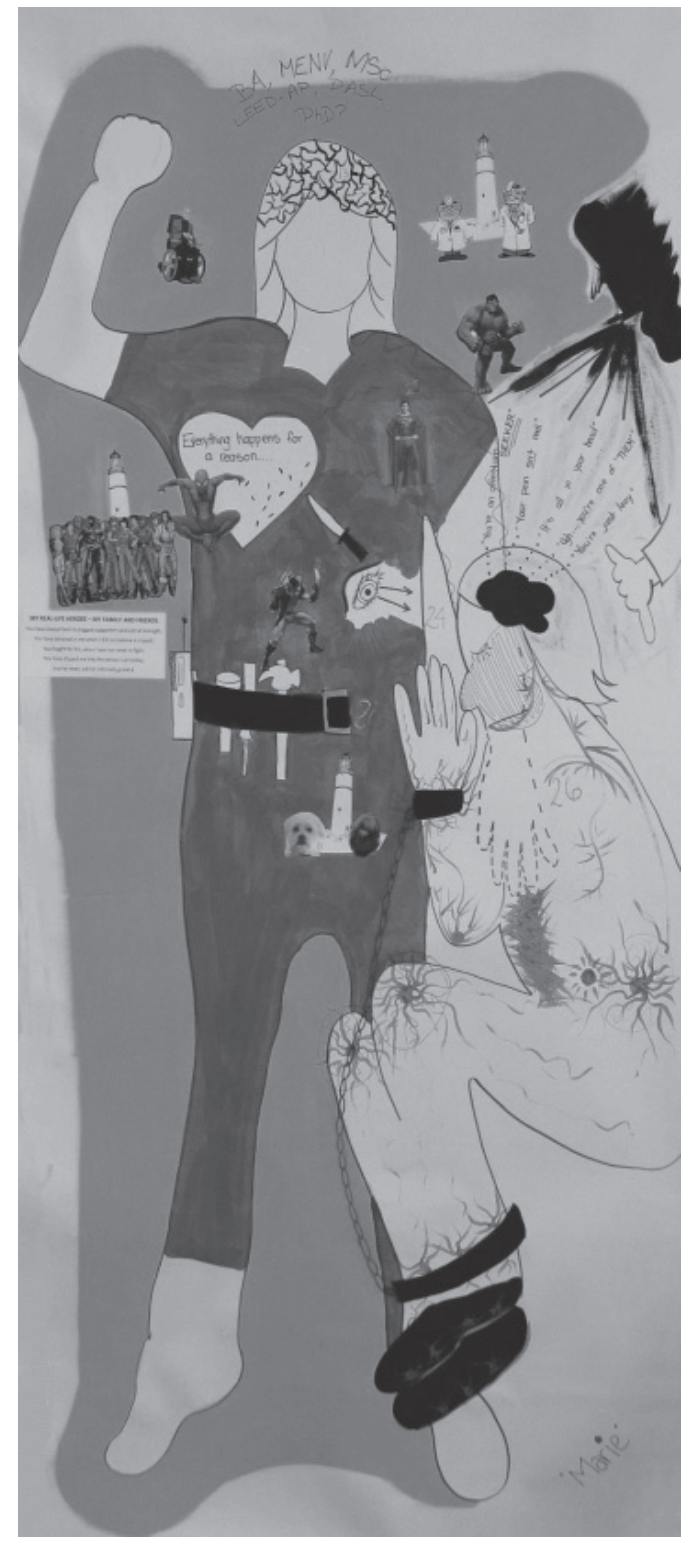

Figure 1: An example of a body map created by study participant Marie (pseudonym) 
reflection in comparison to interviews where participants are expected to answer questions in a relatively quick fashion (Hartman, Mandich, Magalhaes, \& Orchard, 2011).

Sixth, body mapping can help people with chronic conditions experience liberation through the process of storytelling (Frank, 1995). Storytelling is a form of self-expression, which can establish people's credibility and validate the legitimacy of their illnesses. Such narratives can construct an alternative reality to dominant medical discourses, which instruct people on how to behave as good patients and medicalised bodies (Whitehead, 2006). Finally, the process of body mapping can generate societal narratives: socially shared stories (Murray, 2000). Through societal narratives, individual experiences are transformed into collective experiences (Hyden, 1997). The process of collectively sharing narratives is therapeutic, especially for people living with chronic and contested conditions (Kelly \& Clifford, 1997). Societal narratives can involve a cathartic process of witnessing (Frank, 1995). Groups provide forums for participants to publically share their illness narratives, have their experiences validated and repair the losses caused by the biographical disruptions of illness (Bulow, 2004).

In this research, body mapping was conducted within the focus groups where participants could support and inspire each another while producing knowledge about their bodies (Solomon, 2002). People with FM often experience social isolation because they are housebound due to pain and decreased mobility (Soderberg, Lundman, \& Norberg, 1999). Consequently, body mapping within the focus groups had the potential to reduce isolation, promote socialisation and increase self-esteem.

\section{Participant recruitment}

A purposive sample of 35 participants was recruited through support groups in the Greater Toronto Area (GTA) and KitchenerWaterloo (KW). There was no attrition during the data collection. The recruitment strategy involved emailing and telephoning eight GTA support groups. I received responses from six support group leaders who, in turn, emailed my study information letter to their electronic mailing lists; four leaders invited me to their monthly group meeting to present the study information. I was also contacted by the leader of a KW support group who conveyed interest in the study. I subsequently received ethical approval to extend the research geographical parameters to include this region.

\section{Screening interviews}

From January to March 2013, I received indications of interest from 49 potential participants located across Southwestern Ontario. Although some potential participants inquired about the study after I completed presentations in their support groups, most potential participants contacted me via telephone and email after receiving the research information in their support group or from a listserv; the latter group included people who did not attend support group meetings. I screened potential participants using a structured telephone interviews to discuss the research, obtain health histories as well as to confirm a prior medical diagnosis of FM. During these interviews, I also discussed the availability for focus group participation, and interest in body mapping.

Many people with FM are economically and socially marginalised (Soderberg et al., 1999). In order to protect the rights of this population, I both emailed and orally read the research consent form to all potential participants to ensure that they understood the risks and implications of the study before providing consent. To promote trust and transparency, I asked potential participants to specify whether their data should be included or excluded from the research in the event of study drop out. I explained that participant confidentiality would be protected through the following study protocols: using pseudonyms, holding all interviews and 
focus group sessions in private rooms, asking participants to not disclose others' personal details outside of focus group sessions and securing all participants' information in a locked filing cabinet and password-protected computer files.

\section{Emergent design issues}

During the screening interviews, potential participants shared feedback, which led to three ethics amendments regarding data collection methods. First, 13 potential participants were unable to attend the multiple focus group sessions but requested individual interviews to contribute information. Because of the participatory nature of this study, I accommodated these requests by adding interviews to the data collection process. Second, although I initially planned to hold all focus groups in a downtown Toronto location, potential participants voiced concern that lengthy travel would impede study participation. In response to this concern, I divided potential participants into four geographically distinct focus group locations: Midtown Toronto, Mississauga, York Region and KitchenerWaterloo (Table 1). Third, to promote recruitment, I offered the potential focus group participants a $\$ 100$ honorarium divided into two instalments of $\$ 50$. After adding individual interviews, I amended the study budget to additionally provide each interview participant with a \$20 honorarium.

\section{Data collection}

Although this study included both interviews and body mapping within focus groups, the remainder of this article solely focusses on body mapping to assist researchers, who are interested in using this method. Body mapping involved four phases of data collection: preparation, facilitating a pilot focus group, running two focus groups (with minor modification based on pilot group feedback) and returning to the field to reach saturation.

\section{Preparation for using body mapping}

I adapted the art activities outlined in Gastaldo et al.'s (2012) body mapping manual to fit the research topic of healthcare and focus group context. Other preparatory tasks included finding a private room that was accessible and large enough for body mapping. I purchased a wide variety of art supplies (for example, yards of paper, tempera and watercolour paints, pencils, glue, tape, erasers, scissors, pencil sharpeners, rulers, paint brushes, sponges, markers, pencil crayons, felt, tissue paper, construction paper, feathers, gloves and table clothes). I tested these supplies to ensure that they were scent-free because many people with FM have chemical sensitivities. I created my own body map to test the feasibility of the activities (time allocation and concreteness of instructions), and then

Table 1: Overview of Focus Groups

\begin{tabular}{|c|c|c|c|c|}
\hline & Focus Group 1 & Focus Group 2 & Focus Group 3 & Focus Group 4 \\
\hline Location & Midtown Toronto & Kitchener & York Region & Mississauga \\
\hline Time & Mar-May 2013 & Apr-June 2013 & May-Jul 2013 & Sept-Oct 2013 \\
\hline Female Participants & 6 & 7 & 5 & 3 \\
\hline Male Participants & 0 & 0 & 1 & 2 \\
\hline \# of Sessions & 5 & 6 & 6 & 5 \\
\hline \# of Makeup Sessions & 2 & 1 & 0 & 1 \\
\hline Session Frequency & Biweekly & Biweekly & Biweekly & Weekly \\
\hline Duration & 2hrs each session & 2hrs each session & 2hrs each session & $2 \mathrm{hrs}$ each session \\
\hline
\end{tabular}


used this first-hand experience to revise the activities.

I attended an art therapy workshop on visually expressing the healthcare experiences and anticipating the emotional triggers that can occur during this process. I also consulted with a social work colleague, who led therapy groups for trauma survivors, to review potential emotional triggers that research participants could experience. I then developed prevention and intervention strategies to maximise the emotional safety of individual participants and the group as a whole.

\section{Pilot focus group}

From March to May 2013, I facilitated a pilot focus group to assess how many focus group sessions were required for participants to have an adequate time to complete the body mapping process. This pilot group included six participants to create an emotionally safe and intimate environment, only included women due to participant request and met every second week for five focus group sessions (Table 2). Each session lasted two hours each and was digitally recorded.

\section{Session 1}

The objectives of the first focus group session were to: develop group cohesion (for example, emotional safety, trust and rapport), clarify the study focus and to reduce anxiety by demystifying the body mapping process. I arranged the chairs around a table to promote an intimate environment and provided refreshments. As participants arrived, I welcomed them and instructed them to review and complete the paperwork (for example, signing the informed consent forms, confidentiality agreement, honoraria receipts and emergency contact forms). At this stage, participants also self-selected pseudonyms.

After completing the administrative tasks, the participants and I introduced ourselves, reviewed the purpose of the research, discussed confidentiality (for example, not sharing information outside of the group) and co-created a list of rules and responsibilities to establish a safe environment. To prevent participants from potentially dominating the discussion or being silenced, we discussed the importance of being aware of others. I worked with participants to anticipate how they would cope if they experienced emotional triggers, such as speaking with me and/or contacting counselling services; I provided a list of counselling services on the last page of the informed consent form. We also developed strategies for reducing the risk of physical harm. For example, if participants painted their body maps while seated on the floor, they could potentially strain their knees and backs (Hartman et al., 2011). At this point, participants decided if they wanted to create their maps on the floors, walls or tables. This process enabled me to plan ahead in

Table 2: Focus group sessions, themes and activities

\begin{tabular}{|c|c|c|c|c|c|}
\hline & Session 1 & Session 2 & Session 3 & Session 4 & Session 5 \\
\hline Theme & Trust & Health \& illness bios & Healthcare journey & Resilience \& coping & Sharing \\
\hline Activity & Rapport building & Art demo & Personal symbol & Message to others & Finishing touches \\
\hline Activity & Safety rules & Body tracing & Diagnostic journey & Body scanning & Personal narratives \\
\hline Activity & Semi-structured Qs & Self portrait & Care & Support structures & Group process review \\
\hline Activity & & IIIness biography & Healthcare interactions & Drawing the future & \\
\hline Activity & $\begin{array}{l}\text { Group debrief \& } \\
\text { homework }\end{array}$ & $\begin{array}{l}\text { Group debrief \& } \\
\text { homework }\end{array}$ & $\begin{array}{l}\text { Group debrief \& } \\
\text { homework }\end{array}$ & $\begin{array}{l}\text { Group debrief \& } \\
\text { homework }\end{array}$ & Group debrief \\
\hline
\end{tabular}


organising the room for the next session (for example, procuring individual tables and hanging paper on walls).

After safety rules were developed, participants took a refreshment break and then shared their healthcare experiences of being diagnosed with FM. During the final part of this first session, I explained and answered questions about the methodology of body mapping and participants took turns debriefing to achieve closure.

After this focus group session, I reinforced group cohesion by sending participants an email to: thank them for their study commitment; remind them of the date, time and purpose of the next group and share documents (for example, co-created list of group safety rules and next session's body map exercises).

\section{Session 2}

The theme of the second focus group session was health and illness biography. I introduced body mapping by sharing my own body map, showing participants the art supplies, demonstrating how to mix paint colours and reinforcing that participants could use either as few or as many art media as they desired (Figures 2 and 3). To contain anxieties about art, I answered questions about the different ways participants could utilise the supplies.

I gave participants a printed list of questions to promote reflection and guide the development of their body maps. For example, I asked participants to think about a position or posture that represented their current health status, to select colours that represented their posture and to highlight their body shape with paint/markers. Participants partnered with each other and took turns tracing their figures on life-size pieces of paper. Most participants decided to be traced in a front profile, but some selected side profiles (Figure 4). Afterwards, participants chose to either hang their maps on the walls or spread them on five-foot- long tables. Participants were asked to draw self-portraits of their faces and illness biographies. These biographies were based on prompts about what life looked like before and after the onset of FM, as well as visualising the embodied experience and physical locations of FM symptoms.

During the focus group session, I circulated around the room, spending time with each participant to ask reflective questions, probe the meaning behind the colours and shapes and provide encouragement. I avoided

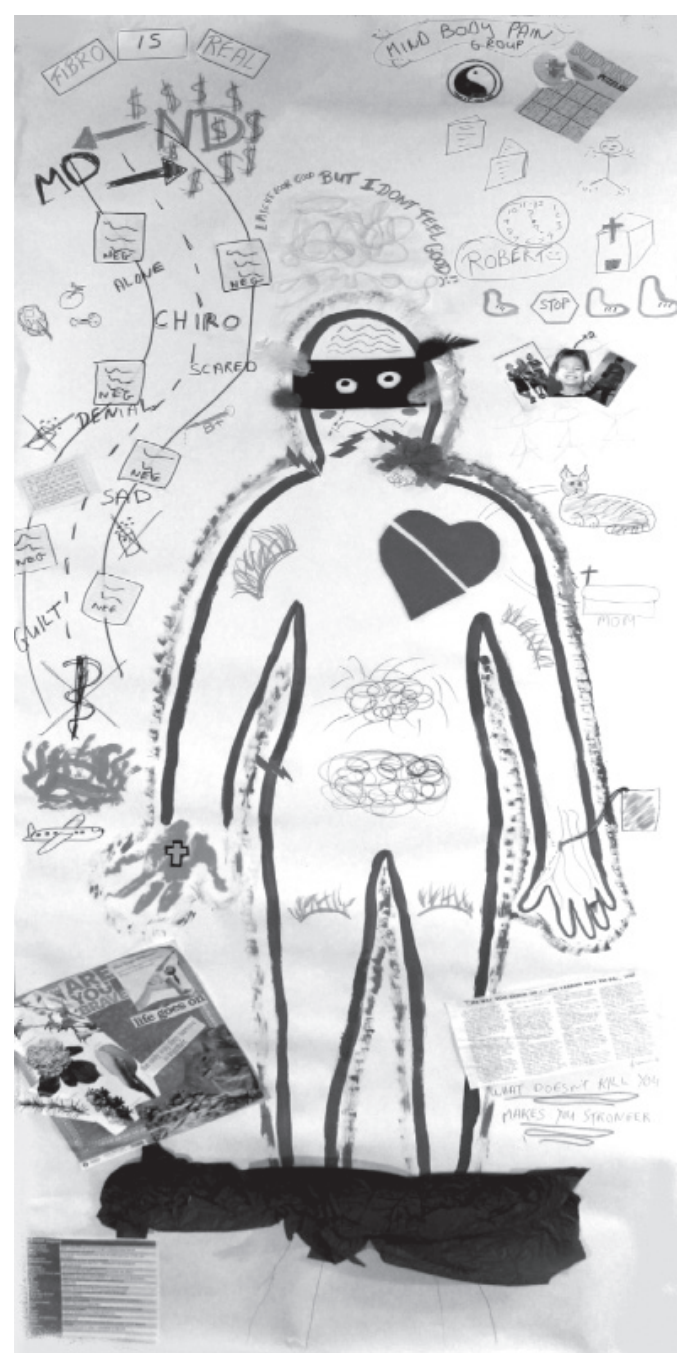

Figure 2: Anna's body map is an example of a multimedia map created with paint, markers, pictures, text, feathers, tissue paper, felt and cotton balls 
imposing my own biases and beliefs. At the end of the session, participants returned to the group for debriefing. Participants were given homework questions and a list of the following focus group session's body mapping activities to ensure the time for reflection.

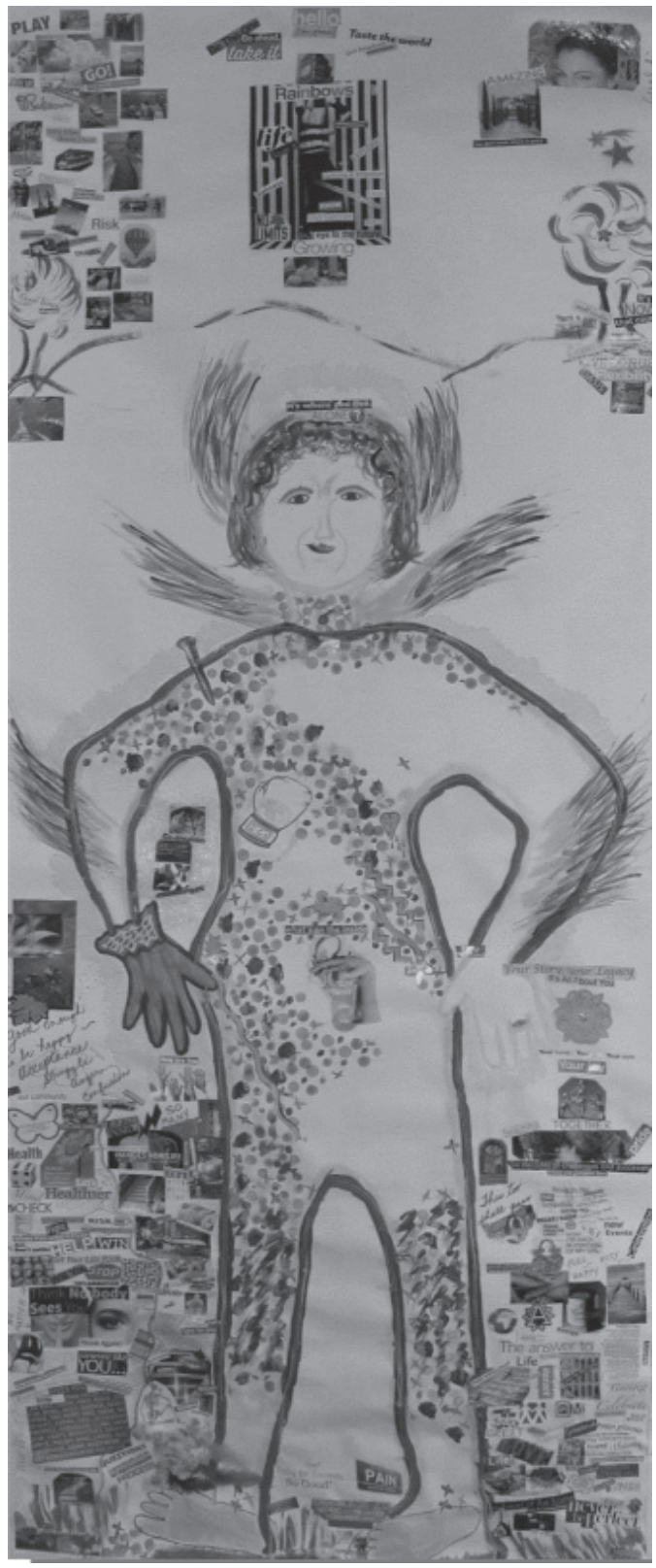

Figure 3: Geraldine's body map is an example of a map primarily created with collage
I digitally recorded all full-group and participant-researcher discussions, as participants' interpretations of their maps would later form the basis of the visual analysis (Gastaldo et al., 2012). I always used two digital recorders in the case of technological problems. The digital recordings had clear sound quality because I moved the devices as group compositions shifted. I positioned the devices to record full-group discussions, which occurred at the beginning and end of each focus group session. I also held the devices while circulating around the room to record all conversations that I had with participants while they created their maps.

The second, third and fourth focus group sessions all had a similar format by beginning with a review of the week's theme and corresponding art exercises, time for breaks and social interaction and ending with a debriefing and review of homework to prepare for the next group's body mapping activities. During each session, participants' added components to their existing body maps based on the session's theme and corresponding activities (Table 2).

\section{Session 3}

The theme of the third focus group session was the healthcare journey. Participants represented their relationships with the healthcare providers by envisioning what positive and negative healthcare interactions looked like and how did the best and worst healthcare interactions make them feel. Participants depicted their diagnostic journeys, self-care strategies and personal symbols and slogans to represent their healthcare experiences.

\section{Session 4}

The theme of the fourth focus group session was resilience and coping. Participants wrote messages to the public about their healthcare experiences. They scanned their bodies to explore all aspects of their healthcare experiences, including issues related to 


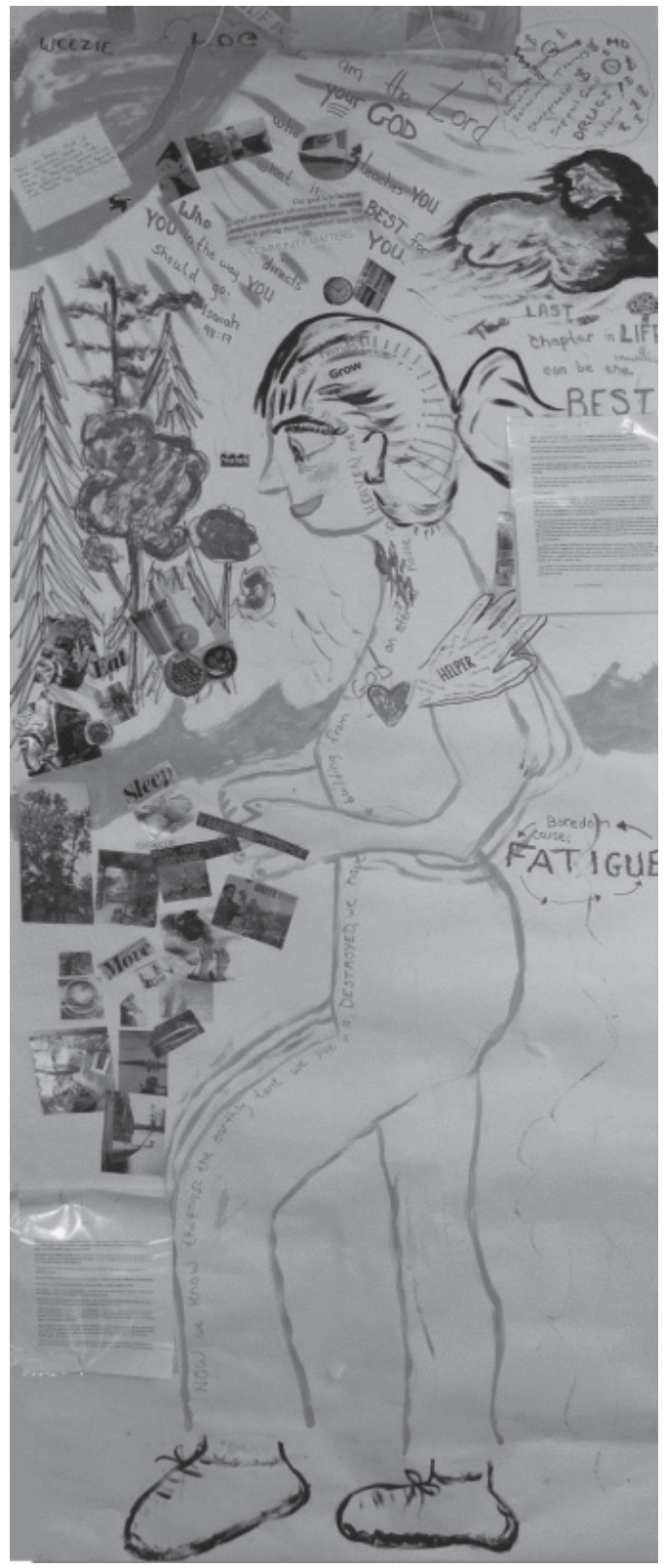

Figure 4: Weezie's body map as an example of tracing the body in side profile

gender, race, social relations and use of services and then depicted the challenges they faced in their interactions with the healthcare providers. They represented their sources of strength and support structures, which helped them cope with healthcare system challenges. Finally, participants drew their future by envisioning their goals and dreams.

\section{Session 5}

During the fifth session, participants spent approximately 15 minutes presenting each body map. I helped participants focus by requesting they share with the group how their body maps represented their healthcare journeys and asking what people should know when they viewed their maps. After these presentations, I facilitated a discussion about whether the process of body mapping prompted ideas or strategies about how healthcare providers could more effectively address patients' physical and emotional needs. Finally, I asked participants to share their experiences about the focus group process and provide feedback for the purpose of strengthening and revising the body mapping methodology.

To reduce the risk of attrition and promote participants' confidence, I facilitated two makeup sessions at participants' homes. During the first makeup session, I helped two participants, who had missed the second focus group session, begin their body maps. During the second makeup session, I helped another participant, who missed three focus group sessions due to FM-related illness, finish her map.

\section{Lessons learned from the pilot group}

During the pilot focus group, I realised that body mapping is a collaborative process between researchers and participants, and thus the co-creation of ideas and artwork is inevitable. I helped participants brainstorm ideas by probing their thoughts about what images they wanted to create and guiding them towards an action plan. However, I tried to reduce researcher bias by adopting a stance of reflexive inquiry, validating participants' visions while consistently reflecting upon my responses and reactions to prevent imposing my own views.

I learned that it was important to give participants the space to organically complete art activities in the order that made 
sense to them. Many participants did not complete the self-portrait (introduced in the second focus group session) until the fifth session because they could not envision what their faces would look like until the end.

Participants' body maps were shaped by their continued work outside of sessions through engagement with the homework exercises. Some participants requested to take their body maps home to work on in between focus group sessions. Participants' engagement in the mapping was also evident by their abilities to look beyond the provided art supplies; some brought their favourite art supplies from home, whereas others asked me to provide additional materials (for example, cotton balls and string to represent symptoms of fibro fog). Another trend was participants selecting images from both on-line and print media sources to paste on their maps; they brought duplicate images to share with fellow participants who, in turn, became inspired to use these images. By sharing resources, participants unintentionally influenced each other and created body maps with overlapping themes. However, I thought it was important to respect participants' collaboration because it fostered community and a spirit of collective empowerment. During data analysis, I addressed how the research findings were potentially affected by both the collaboration and movement of body maps between the focus groups and homes.

\section{Facilitating further focus groups}

After receiving feedback from pilot focus group participants, I revised the body mapping exercises and then concurrently facilitated a focus group with seven female participants in Kitchener and a mixedgender focus group with one male and five female participants in the York region. These two focus groups had a similar format to the sessions in the pilot focus group except minor variations were made to the exercise guide. I added an extra session due to participants' feedback that more time was required to complete the exercises.

\section{Returning to the field}

After completing three focus groups, I sent a report of preliminary findings to the research thesis committee. Although the study included men and women, only two men had participated. Thus, the committee and I decided that I would return to the field to explore gender differences in healthcare experiences. To achieve this objective, I facilitated a fourth mixed-gender focus group with two male and three female participants in Mississauga. Although the format was similar to the previous three focus groups, I facilitated the sessions on a weekly basis, rather than every two weeks, to expedite the data collection process. Compared to the previous focus groups, this group had fewer participants, and therefore I reduced the number of group sessions from six to five. By having fewer participants, I was able to spend more time with each participant during their body mapping activities. Based on the participant's feedback, I began each focus group session with a 5-minute meditation to help group members feel more relaxed before engaging in body mapping. The participants and I noted that after the meditation, there was a calming change in the room's energy.

\section{Data analysis}

I concurrently collected and analysed the verbal and visual focus group data. After each focus group session, I wrote field notes to reflect upon the group dynamics and the illuminating themes that arose during the body mapping. These notes captured both the verbal and non-verbal richness of the data, including participants' use of humour and intensity of their emotions. I hired research assistants to transcribe the verbal digital recordings. I cleaned the transcripts of all identifying information, uploaded these transcripts into the qualitative software program NVivo 10 (QSR International) and used constructivist grounded theory to code and analyse the transcripts (Charmaz, 2006). I selected constructivist grounded theory, rather than traditional forms of grounded theory, because this approach assumes 
that participants experience a multitude of realities (Charmaz, 2006). Constructivist grounded theory fitted with the framing of experience as constructed by intersecting identities and experiences.

This inductive approach involved reading the transcripts multiple times, coding lineby-line and creating initial codes grounded in the data. After the development of initial codes, I refined these codes and developed axial codes, which involved organising the data into categories and subcategories. This organisation of data led to the identification of theoretical codes with the objective of obtaining "thick description" about participants' experiences (Charmaz, 2006), as well as to constantly comparing the data. In the final analytic stage, I developed a theory grounded in the data about healthcare interactions.

In addition to the transcripts, I analysed the participants' body maps. Unfortunately, there is a dearth of literature in the health sciences and social sciences about methods for visual analysis. However, Gastaldo et al. (2012) explained that body maps:

[S]hould be analysed in their integrity, which includes the process of creating it (verbatim and field notes), the body map itself, and the narratives that accompany it (testimonio and key). The purpose of the analysis is not to psychologically evaluate the participants through their art, but to gain insight into certain aspects of their logic, aspirations, desires, material circumstances and ways of handling particular issues (p. 18).

Given the importance of balancing participants' maps, verbal narratives and creative processes, I developed a multilayered visual coding scheme. This coding scheme was influenced by constructivist grounded theory and involved the following eight stages:

First, I followed an inductive approach by reviewing all of the body maps (as one would repeatedly read transcripts) to familiarise myself with the data. This approach involved rolling out the life-size body maps on a long table to examine all parts of the maps. Second, I organised the visual data by photographing the body maps and uploading these photographs into NVivo 10 (Figure 5). I analysed the life-size body maps rather than the photographs of the maps because many of the hand-drawn details could not be seen in the photographs. However, the rationale behind uploading the photographs was to create a system of organisation. I used NVivo to consistently organise the codes and memos, which emerged from the visual analysis, and to ensure that both the visual and verbal data were contained within the same software programme. This process enabled me to later compare and merge codes from both the visual and verbal data.

Third, I created initial codes based on the similarities and differences in the: use of colour; themes and discourses; types of representations (for example, words, picture collages and hand-drawn images); size, repetition and location (for example, symbols

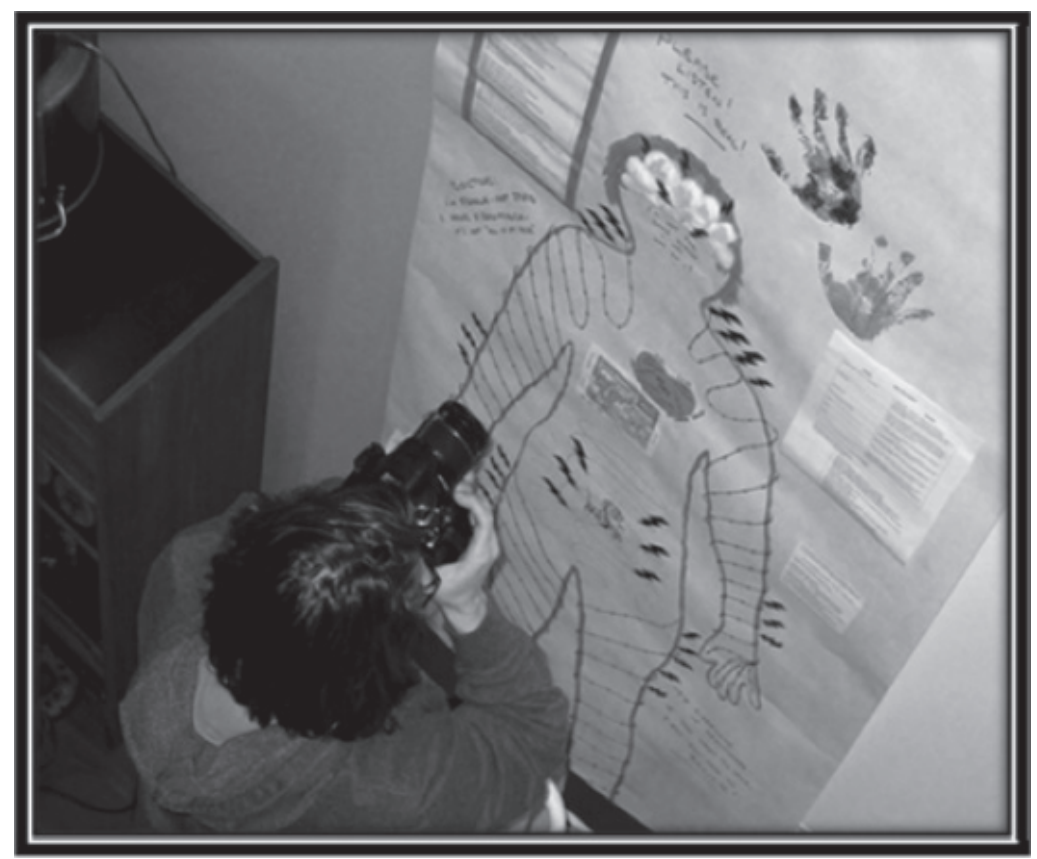

Figure 5: Photographing the body maps for the purpose of data analysis 
situated inside and outside of the body) of the images and words.

Fourth, I compared the participants' body maps to their audio-recorded verbal presentations of their maps, which occurred during the final session of each focus group. Because this research was participatory, it was important to honour and not misinterpret the meanings participants' ascribed to their maps. Furthermore, this process of matching participants' images to their narratives was a method of ensuring that the initial codes were grounded in the data. Through this process, I also refined the codes by renaming and redefining them to improve the clarity of meaning.

Fifth, I grouped the codes into three themes: conceptual content, tone and elements of design. Conceptual content refers to the healthcare-related themes represented by words and images in the body maps. Tone refers to the mood evoked through the images and words that participants' used to represent their positive and negative healthcare experiences. Elements of design refer to the visual aesthetics of the body maps; this is a conceptual framework borrowed from fine art theory. For centuries, the elements of design, which are considered to be universal, have helped guide how artists have created their artwork and art critics have interpreted these works. The elements of design include: line (horizontal, vertical, diagonal lines); colour; value (the hue and tone of the colour); shape (the two-dimensional outline of objects); form (the three-dimensional creation of objections and area through shading); space (the positive space of the object and negative space surrounding the object) and texture. Within a piece of art, repeated elements (for example, colour and line) and proportion (for example, evenly balanced shapes) evoke a sense of visual harmony, unity, movement and rhythm, while a variety of elements creates visual interest. I used several of these elements of design - specifically colour, texture, shape and space to guide my analysis. I also looked at how these elements created visual harmony, rhythm, movement and interest.
Visual aesthetics were relevant in this particular social work study because many participants discussed how certain elements of design (for example, colour and shape) symbolised their health and illness identities (see Figure 6 example). In other words, visual aesthetics were grounded in the data.

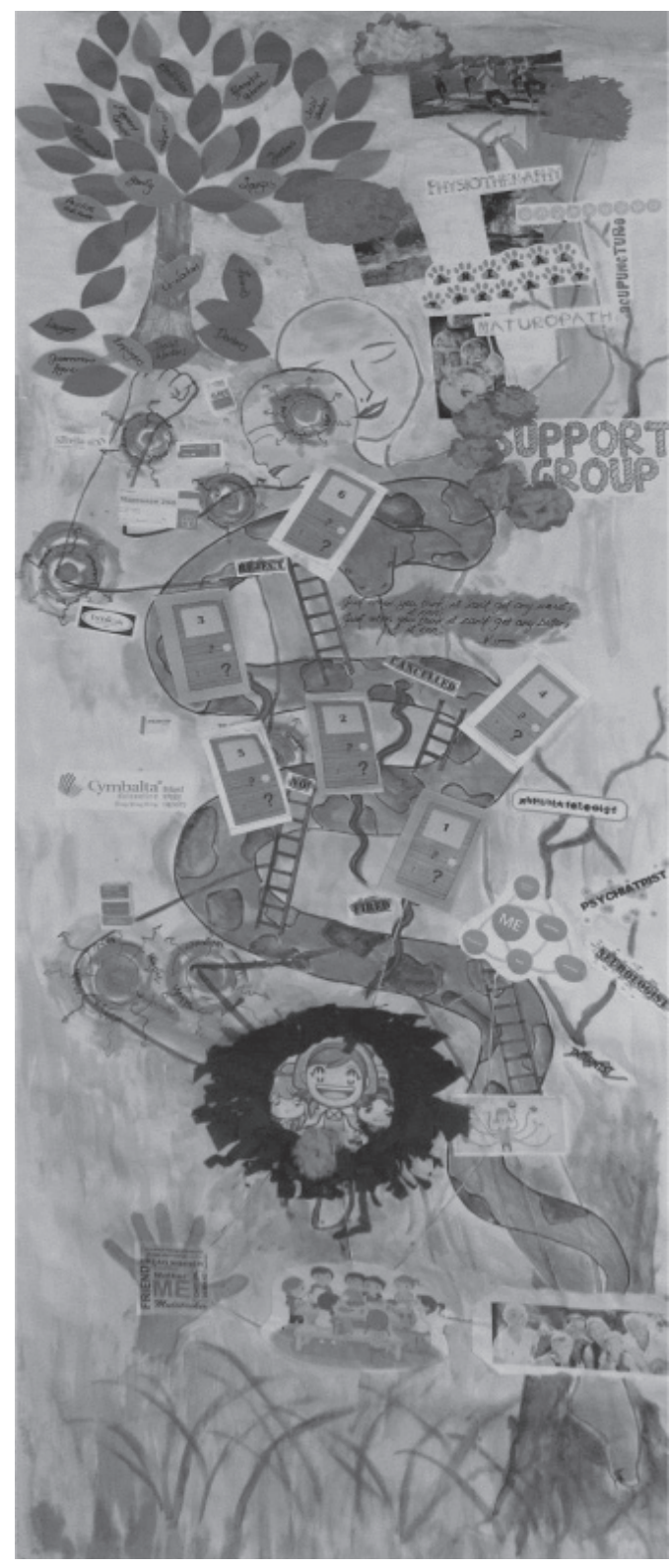

Figure 6: Hope explained that she drew her healthy face larger and higher than her unwell face to symbolise resilience 
The sixth stage of visual analysis involved exploring how the themes of conceptual content, tone and elements of design were co-constructed both within and across the groups. For example, the image of healthcare as a journey was repeatedly constructed by participants belonging to both the same and different focus groups. These withingroup commonalities highlighted that participants shared ideas with each other as they created their maps. In comparison, the across-group commonalities signified both the universality of certain images and metaphors. These commonalities also shed light as to the ways in which I was inspired by the participants, thereby unintentionally co-constructing meaning across groups. For example, at times, when I described body-mapping exercises to participants, I illustrated these exercises with themes that arose in other focus groups. These themes may have resonated with certain participants and influenced their artistic process.

The seventh stage of visual analysis focussed on intersectionality. Within each of the three themes, I selected a variety of salient codes and then examined the differences in these codes. For example, in the code "negative healthcare experiences," which was categorised under the theme of conceptual content, I compared the images created by male and female participants. I compared these images with the transcripts to capture both the verbal and non-verbal meanings. This process was deductive because I specifically examined the participants' depictions of how their gender, age, race, class, culture and religion influenced their interactions with healthcare providers.

The eighth stage involved narrowing the focus of the visual analysis for the purpose of addressing the specific research question. In particular, I focused on the codes that were within the theme of conceptual content, described healthcare experiences and illustrated the salient concepts emerging from the transcript analysis.

\section{Findings}

Although this is a largely conceptual paper, describing the study methodology, it is important to provide an overview of the key findings that emerged through body mapping. This study found that: (a) participants experienced structural barriers to accessing healthcare services and unsupportive attitudes from the healthcare providers; (b) participants' healthcare experiences were affected by their gender, age, class and race and (c) participants used self-management strategies to cope with healthcare barriers.

\section{The therapeutic aspects of body mapping}

Although to conduct this research body mapping was adapted from an art therapy to a research method (Gastaldo et al., 2012), the therapeutic value of body mapping was still evident. The therapeutic value was highlighted by the lack of attrition during this research despite the significant time commitment required to take part. Many participants reported that the process of body mapping increased their sense of social connection because it was the first time they realised that they were not alone in their suffering and that others had similar symptoms and healthcare struggles. After the completion of focus groups, some participants maintained their connections by exchanging emails and meeting for coffee on an informal basis. I declined participants' invitation to join these informal gatherings to maintain my researcher role. Furthermore, on several occasions, I observed that body mapping had a containing quality; participants, who came into the focus group sessions tearful because they were having difficult days, appeared calmer after working on their maps.

Based on these experiences, I suggest that researchers need to be trained in group facilitation to ensure that participants' feel emotionally safe throughout the body mapping process. If researchers do not have training to manage triggers and emotional 
distress, then they need to collaborate with practitioners to provide on-site support to participants as required. Researchers engaging participants in sensitive topics should always provide a list of support services to access should they feel the need.

\section{Conclusion}

To date, I have exhibited the body maps in three community art galleries in the Ontario cities of Toronto, Kitchener and London. Although participants were given the choice to keep their body maps after the exhibitions, many donated their maps to be showcased in the future. All participants provided informed consent for their body maps to be photographed for use in further knowledge translation endeavours; I will have these photographs printed on banner fabric to improve the portability of the body maps for display in healthcare settings. I will also design a website to showcase the body maps as an educational tool for FM and healthcare community.

Facilitating groups is a traditional form of intervention in social work practice as well as a method of qualitative inquiry in social work research. This research has contributed to the social work field by highlighting the importance of group process in the context of body mapping research and reflecting the profession's commitment to social justice, applied research and innovative practices. Social change has been creatively fostered with the research findings being used to generate a better understanding of the healthcare experiences of people with FM.

\section{References}

Baerg, S. (2003). "Sometimes there just aren't any words": Using expressive therapy with adolescents living with cancer. Canadian Journal of Counselling, 37(1), 65-74. Retrieved from https://libproxy.wlu.ca/login?url=http:// search.proquest.com/docview/195792767?account $\mathrm{id}=15090$

Bulow, P. H. (2004). Sharing experience of contested illness by storytelling. Discourse \& Society, 15(1), 33-53. doi:10.1177/0957926504038943

Charmaz, K. (2006). Constructing grounded theory. A practical guide through qualitative analysis. London, United Kingdom: Sage.
Cornwall, A. (1992). Body mapping in health RRA PRA. RRA Notes, 16, 69-76. Retrieved from https:// www.researchgate.net/profile/Andrea_Cornwall/ publication/267720669_Body_mapping_in_health_ RRAPRA/links/54efa1390cf25f74d722809a.pdf

Davy, C., Magalhaes, L. V., Mandich, A., \& Galheigo, S. M. (2014). Aspects of the resilience and settlement of refugee youth: A narrative study using body maps. Cadernos de Terapia Ocupacional da UFSCar, São Carlos, 22(2), 231-241. doi:10.4322/cto.2014.045

Devine, C. (2008). The moon, the stars, and a scar: Body mapping stories of women living with HIV/AIDS. Border Crossings, Winnipeg, 27(1), 58-65. Retrieved from http://www.catie.ca/pdf/bodymaps/BC_105_ BodyMapping.pdf

Eisner, E. (2006). Does arts-based research have a future? Studies in Art Education, 48(1), 9-18. doi:10.2307/25475802

Fitzcharles, M. A., Ste-Marie, P., Goldenberg, D. L., Pereira, J. X., Abbey, S., Choinière, M., ..., Shir, Y. (2013). 2012 Canadian guidelines for the diagnosis and management of fibromyalgia syndrome: Executive summary. Pain Research \& Management: The Journal of the Canadian Pain Society, 18(3), 119-126. Retrieved from https:// libproxy.wlu.ca/login?url=http://search.proquest.com/ docview/1371827494? accountid=15090

Frank, A. W. (1995). The wounded storyteller: Body, illness, and ethics. Chicago, IL: University of Chicago Press.

Gastaldo, D., Magalhaes, L., Carrasco, C., \& Davy, C. (2012). Body mapping as research: Methodological considerations for telling the stories of undocumented workers through body mapping. Retrieved from http:/ www.migrationhealth.ca/undocumented-workers-ontario/ body-mapping

Hartman, L. R., Mandich, A., Magalhaes, A., \& Orchard, T. (2011). How do we 'see' occupations? An examination of visual research methodologies in the study of human occupation. Journal of Occupational Science, 18(4), 292-305. doi:10.1080/14427591.2011.610776

Hill Collins, P. (2015). Intersectionality's definitional dilemmas. Annual Review of Sociology, 41, 1-20. doi:10.1146/annurev-soc-073014-112142

Hyden, L. C. (1997). Illness and narrative. Sociology of Health \& IIIness, 19(1), 48-69. doi:10.1111/j.1467-9566.1997.tb00015.x

Kelly, P., \& Clifford, P. (1997). Coping with chronic pain: Assessing narrative approaches. Social Work, 42(3), 266-277. doi:10.1093/sw/42.3.266

MacGregor, H. N. (2008). Mapping the body: Tracing the personal and the political dimensions of HIV/AIDS in Khayelitsha, South Africa. Anthropology \& Medicine, 16(1), 85-95. doi:10.1080/13648470802426326

Maina, G., Sutankayo, L., Chorney, R., \& Caine, V. (2014). Living with and teaching about HIV: Engaging nursing students through body mapping. Nurse Education Today, 34(4), 643-647. doi:10.1016/j.nedt.2013.05.004

Mitchell, L. M. (2006). Body and illness: Considering Visayan Filipino children's perspectives within local and global relationships of inequality. Medical Anthropology, 25(4), 331-373. doi:10.1080/01459740601025856

Murray, M. (2000). Levels of narrative analysis in health psychology. Journal of Health Psychology, 5(3), 337-347. doi:10.1177/135910530000500305 
Ramsuran, A., \& Lurwengu. F. (2008). Relations of power in different spaces: An exploration of the schooling experiences of children in an HIV/AIDS context. Journal of Psychology in Africa, 18(3), 393-399. doi:10.1080/143 30237.2008.10820211

Senior, K., Helmer, J., Chenhall, R., \& Burbank, V. (2014). 'Young clean and safe?' Young people's perceptions of risk from sexually transmitted infections in regional, rural and remote Australia. Culture, Health \& Sexuality: An International Journal for Research, Intervention and Care, 16(4), 453-466. doi:10.1080/13691058.2014. 888096

Soderberg, S., Lundman, B., \& Norberg, A. (1999). Struggling for dignity: The meaning of women's experiences of living with fibromyalgia. Qualitative Health Research, 9(5), 575-587. doi:10.1177/104973299129122090

Solomon, J. 2002. "Living with X": A body mapping journey in time of HIV and AIDS. Facilitator's Guide. Psychosocial Wellbeing Series. Johannesburg: REPSSI. Retrieved from http://www.repssi.org/index.php?option=com_ content $\&$ view $=$ article\&id=46\&ltemid $=37$.

Sweet, E. L., \& Escalante, S. O. (2015). Bringing bodies into planning: Visceral methods, fear and gender violence. Urban Studies, 52(10), 1826-1845. doi:10.1177/0042098014541157

Tarr, J., \& Thomas, H. (2011). Mapping embodiment: Methodologies for representing pain and injury. Qualitative Research, 11(2), 141-157. doi:10.1177/1468794110394067

Whitehead, L.C. (2006). Quest, chaos and restitution: Living with chronic fatigue syndrome/myalgic encephalomyelitis. Social Science \& Medicine, 62(9), 2236-2245. doi:10.1016/j.socscimed.2005.09.008

Wolfe, F. (2009). Fibromyalgia wars. The Journal of Rheumatology, 36(4), 671-678. doi:10.3899/ jrheum.081180 